\title{
Study of fetomaternal outcome in eclampsia
}

\author{
Manju Agarwal, Akanksha Gautam*
}

Department of Obstetrics and Gynaecology, Jhalawar Medical College, Jhalawar, Rajasthan, India

Received: 26 July 2020

Accepted: 04 September 2020

\section{*Correspondence:}

Dr. Akanksha Gautam,

E-mail: airyblues@gmail.com

Copyright: () the author(s), publisher and licensee Medip Academy. This is an open-access article distributed under the terms of the Creative Commons Attribution Non-Commercial License, which permits unrestricted non-commercial use, distribution, and reproduction in any medium, provided the original work is properly cited.

\section{ABSTRACT}

Background: Eclampsia is a life-threatening emergency that continues to be a major cause of maternal and perinatal mortality. The purpose of our study was to analyse the trend of eclampsia in a tertiary care teaching institute and to find out the fetomaternal outcomes of eclampsia.

Methods: A retrospective epidemiological study was undertaken in the department of Obstetrics and Gynaecology, Jhalawar medical college, Jhalawar during the period 'September 2018 to August 2019'. Women who presented as eclampsia or developed eclampsia during hospital stay were included in the study. Data analysed included various maternal parameters, fetal parameters, and the outcome of the pregnancy.

Results: The incidence of antepartum eclampsia was $(0.92 \%)$. High risk associated factors were primigravida (65.90\%), low maternal age (21-30 years), illiteracy, and inadequate antenatal care. Caesarean section was the mode of delivery in 48 cases $(54.54 \%)$ most common indication was unfavourable cervix, $80.6 \%$ women had antepartum eclampsia and $68.18 \%$ women had severe preeclampsia. There was $6.8 \%$ maternal mortality, attributed to pulmonary edema and acute renal failure. Perinatal mortality was $14.77 \%$ with 8 still births and 5 neonatal deaths. Prematurity complicated $46.66 \%$ pregnancies. Thirty neonates were admitted to NICU.

Conclusions: Eclampsia is one of the important causes of maternal and perinatal morbidity and mortality due to lack of proper antenatal care, low socio-economic status, and lack of education. It can be concluded that better antenatal care, early recognition of disease, timely referral, early initiation of treatment and termination of eclamptic patients improves outcome. Management of eclamptic patients should be performed at tertiary care centres, where ICU facilities, NICU facilities, and multidisciplinary units are available.

Keywords: Caesarean section, Eclampsia, Fetomaternal outcome, NICU, Prematurity, Pulmonary edema

\section{INTRODUCTION}

Hypertensive disorders complicate about $10 \%$ of all pregnancies worldwide. Hypertension, along with haemorrhage and infection form a deadly triad accounting for a major share of maternal morbidity and mortality. ${ }^{1}$

Eclampsia is defined as the onset of convulsions or coma during pregnancy or post-partum in a patient who has signs and symptoms of preeclampsia. ${ }^{1}$ Eclampsia is a life threatening emergency that continues to be a major cause of serious maternal morbidity and is still the leading cause of maternal mortality worldwide. Complicated cases and mismanaged cases are responsible for most maternal deaths, which are usually due to intracerebral hemorrhage, pulmonary edema, or renal, hepatic, or respiratory failure.' In addition, its presence is usually associated with high perinatal mortality and morbidity. The main causes of perinatal mortality and neonatal morbidity from eclampsia are preterm delivery, fetal growth retardation, and abruptio placentae. ${ }^{2}$

WHO estimates the incidence of preeclampsia to be seven times higher in developing countries $(2.8 \%$ of live births) than in developed countries (0.4\%). A preeclamptic woman in a developing country is three times more likely to progress to eclampsia than a woman 
in a developed country. WHO estimates that eclampsia develops in $2.3 \%$ of preeclamptic women in the developing world, compared with $0.8 \%$ of preeclampsia cases in developed countries. ${ }^{1}$ Eclampsia is associated with elevated maternal and fetal morbidity and mortality. The World Health Organisation (WHO) estimates that at least $16 \%$ of maternal deaths in developing countries result from preeclampsia and eclampsia. ${ }^{3}$ Approximately 63,000 pregnant women die every year because of these conditions. Preeclampsia/eclampsia ranks second only to haemorrhage as a specific, direct cause of death

Preeclampsia is a multisystem disorder where the release of one or more factors damages the vascular endothelial cells throughout the maternal circulation leading to multisystem dysfunction. ${ }^{4}$ There is currently no single cost effective and reliable screening test for preeclampsia and there are no well-established measures for primary prevention.

Other than early detection of preeclampsia, there are no reliable tests or symptoms for predicting the development of eclampsia. Hypertension is considered the hallmark for the diagnosis of eclampsia. But in many of the cases onset of preeclampsia is often insidious and pathological changes start early in the course of the disease and symptoms usually occur late. In $16 \%$ of the cases, hypertension may be absent. ${ }^{5}$ In a series of 399 women with eclampsia, substantial Proteinuria was present in only $48 \%$ of the cases, whereas Proteinuria was absent in $14 \%$ of the cases. ${ }^{5}$

Most of the studies related to eclampsia have been done in developed countries whereas eclampsia is much more common in developing countries. Also, most of the existing studies are retrospective in nature. The incidence of eclampsia in India has been mostly calculated based on personal communication from various institutions and the true incidence remains unknown. Furthermore, various anticonvulsant therapies are used for management of eclampsia especially in the community hospitals, despite recent studies showing many of those therapies not to be so useful. The influence of those various regimens in affecting the morbidity and mortality of mother and foetus need further evaluation.

The present study was undertaken to analyse the incidence of eclampsia, to assess the maternal and fetal outcome in patients of eclampsia and to evaluate various factors influencing this outcome, so that preventive measure could be suggested.

\section{METHODS}

This retrospective study was conducted in Obstetrics and Gynecology Department, Jhalawar Medical College, Jhalawar, India during September 2018 to August 2019. The present study aims to determine the factors affecting the maternal and perinatal outcome of eclamptic mothers. Women with other causes of convulsions were excluded.

\section{Inclusion criteria}

Patients with generalized tonic-clonic convulsions during pregnancy/labour/within 7 days of delivery were included.

\section{Exclusion criteria}

Women who were known case of epilepsy; and seizures due to metabolic disturbances, space occupying lesions or intra cerebral infections.

The case records of all eclamptic women were reviewed. Parameters collected and analysed with regard to maternal age, parity, booking status, gestational age, blood pressure and laboratory test parameters. Mode of delivery, maternal and perinatal outcomes were also studied.

All patients received magnesium sulphate $\left(\mathrm{MgSO}_{4}\right)$ except those with contraindications (absent knee jerk, respiratory depression, urine output $<30 \quad \mathrm{ml} / \mathrm{hour}$ ) received phenytoin. Patients received $\mathrm{MgSO} 4$ as per Pritchard regime (loading dose $4 \mathrm{gm}$ of magnesium sulphate as a $20 \%$ solution intravenously at a rate not exceeding $1 \mathrm{gm} / \mathrm{min}$, accompanied by $10 \mathrm{gm}$ of magnesium sulphate solution, one half (5 gm) injected deep intramuscular in upper outer quadrant of each buttock with a 3 inch long 20 gauge needle. This was followed by maintenance dose: Every four hour, thereafter given $5 \mathrm{gm}$ of $50 \%$ solution of magnesium sulphate injected deep i.m. in upper outer quadrant of alternate buttock. Magnesium sulphate was discontinued 24 hours after delivery.

After stabilization obstetric management was carried out. All antepartum eclampsia patients were terminated irrespective of gestational age.

\section{RESULTS}

A total number of 9502 women delivered during the defined time period. Out of them, 88 women were diagnosed as cases of eclampsia making an incidence of eclampsia to be 9.26 per 1000 deliveries.

Table 1: Demographic characteristics.

\begin{tabular}{|ll|}
\hline Characteristics & No. of cases $(\%)$ \\
\hline Maternal age (years) & \\
\hline$<20$ & $12(13.63)$ \\
\hline $21-30$ & $56(63.63)$ \\
\hline$>30$ & $20(22.72)$ \\
\hline Parity & \\
\hline Primigravida & $58(65.90)$ \\
\hline Multigravida & $30(34.09)$ \\
\hline Booking status & \\
\hline Booked & $31(35.22)$ \\
\hline Unbooked & $57(64.77)$ \\
\hline
\end{tabular}


Table 1 demonstrates demographic characteristics of patients. Eclampsia was more common in the age group $20-30$ years $(63.63 \%)$, primigravidae $(65.90 \%)$ and $(64.77 \%)$ patients were unbooked.

Table 2: Type of eclampsia.

\begin{tabular}{|ll|}
\hline Type of eclampsia & No. of cases $(\%)$ \\
\hline Antepartum & $71(80.6)$ \\
\hline Intrapartum & $6(6.9)$ \\
\hline Postpartum & $11(12.5)$ \\
\hline Total & $88(100)$ \\
\hline
\end{tabular}

Among 88 cases, $71(80.6 \%)$ cases were antepartum eclampsia, $6(6.9 \%)$ were intrapartum eclampsia and 11 $(12.5 \%)$ cases were postpartum eclampsia (Table 2).

Table 3: Gestational age at the onset of fit.

\begin{tabular}{|ll|}
\hline Gestational age (weeks) & No. of cases $(\%)$ \\
\hline$<34$ & $16(20.77)$ \\
\hline $\mathbf{3 4 - 3 7}$ & $28(36.3)$ \\
\hline$>\mathbf{3 7}$ & $33(42.8)$ \\
\hline Total & $77(100)$ \\
\hline
\end{tabular}

Majority of patients $33(42.8 \%)$ presented at gestational age >37 weeks, $28(36.3 \%)$ patients between 34-37 weeks, and $16(20.77 \%)$ at $<34$ weeks (Table 3).

Table 4: Blood pressure at presentation.

\begin{tabular}{|ll|}
\hline Blood pressure & No. of cases $(\%)$ \\
\hline$>\mathbf{1 6 0} / \mathbf{1 1 0}$ & $60(68.18)$ \\
\hline $\mathbf{1 6 0 / 1 1 0}$ & $28(31.81)$ \\
\hline Total & $88(100)$ \\
\hline
\end{tabular}

$68.18 \%$ patients presented with severe hypertension with blood pressure $>160 / 110$, and $31.81 \%$ patients had blood pressure <160/110 (Table 4).

Table 5: Mode of delivery.

\begin{tabular}{|ll|}
\hline Mode of delivery & No. of cases $(\%)$ \\
\hline Vaginal & $40(45.4)$ \\
\hline LSCS & $48(54.5)$ \\
\hline Total & $88(100)$ \\
\hline
\end{tabular}

Table 6: Indication of caesarean section in eclamptic patient.

\begin{tabular}{|ll|}
\hline Indication & No. of cases $(\%)$ \\
\hline Unfavourable cervix & $30(62.5)$ \\
\hline Failed induction & $8(16.6)$ \\
\hline Cephalopelvic disproportion & $4(8.33)$ \\
\hline Fetal distress & $6(12.5)$ \\
\hline Total & $48(100)$ \\
\hline
\end{tabular}

$48(54.5 \%)$ patients were delivered by lower segment caesarean section, while $40(45.4 \%)$ patients delivered vaginally (Table 5).

The most common indication of caesarean section was unfavourable cervix in $30(62.5 \%)$ patients followed by failed induction in $8(16.6 \%)$ patients, fetal distress in 6 $(12.5 \%)$ patients and cephalopelvic disproportion in 4 $(8.33 \%)$ patients (Table 6).

Acute renal failure, abruptio placentae and postpartum haemorrhage was present in $4.54 \%$ cases. Pulmonary edema and HELLP developed in $6.81 \%$ of cases. Maternal death occurred in $6.81 \%$ of cases. Of the 19 maternal deaths for the period, eclampsia contributed to 6 deaths, with a case fatality rate of $6.81 \%$. Pulmonary edema was the commonest cause of death in 4 cases. In 2 cases cause of death was acute renal failure, least among complications were coagulopathy $(3.40 \%)$, cortical blindness $(2.27 \%)$ and cerebrovascular accidents $(2.27 \%)$ (Table 7).

Table 7: Maternal morbidity and mortality due to eclampsia.

\begin{tabular}{|ll|}
\hline Complications & No. of cases $(\%)$ \\
\hline Acute renal failure & $4(4.54)$ \\
\hline Cerebrovascular accidents & $2(2.27)$ \\
\hline HELLP syndrome & $6(6.81)$ \\
\hline Pulmonary edema & $6(6.81)$ \\
\hline Coagulopathy & $3(3.40)$ \\
\hline Abruptio placentae & $4(4.54)$ \\
\hline Post-partum haemorrhage & $4(4.54)$ \\
\hline Cortical blindness & $2(2.27)$ \\
\hline Death & $6(6.8)$ \\
\hline
\end{tabular}

Table 8: Perinatal morbidity and mortality.

\begin{tabular}{|lll|}
\hline Perinatal outcome & No. of cases (\%) \\
\hline NICU admissions & $30(34.09)$ \\
\hline & $\begin{array}{l}\text { Intrauterine growth } \\
\text { restriction }\end{array}$ & $6(20)$ \\
\cline { 2 - 3 } NICU & Prematurity & $14(46.66)$ \\
\cline { 2 - 3 } admissions & $\begin{array}{l}\text { Meconium aspiration } \\
\text { syndrome }\end{array}$ & $3(10)$ \\
\cline { 2 - 3 } & Birth asphyxia & $4(13.33)$ \\
\cline { 2 - 3 } & Respiratory distress & $3(10)$ \\
\hline Still birth & $8(9.09)$ \\
\hline Neonatal death & $5(5.68)$ \\
\hline Perinatal mortality & $13(14.77)$ \\
\hline
\end{tabular}

30 babies had some perinatal morbidity and required NICU admission. Prematurity (46.66\%), Intrauterine growth restriction (20\%) and birth asphyxia (13.33\%) were the most common causes of perinatal morbidity. The other common causes were respiratory distress and meconium aspiration syndrome. Perinatal mortality was $(14.77 \%)$ which included still births $(9.09 \%, 7$ were 
intrauterine fetal death on admission) and neonatal death $(5.68 \%)$ (Table 8$)$.

\section{DISCUSSION}

Eclampsia was more common in the age group 21-30 years $(63.63 \%)$, similar finding was reported in the studies conducted by Mahalaxmi et al and Kannar et al. ${ }^{6,7}$

Gravidity also influences the incidence of eclampsia. In present study majority $58(65.90 \%)$ of patients were primigravida. Sibai et al and Efetie et al also reported similar findings in their studies. ${ }^{2,8}$

Majority $(64.77 \%)$ of patients were unbooked. Lack of antenatal care is one of the important risk factors for the development of eclampsia. In a study by Pannu in North India $56.6 \%$ of women had received no antenatal care before the onset of convulsions. ${ }^{9}$ And in the study conducted by Nobis et al $93.4 \%$ percent cases had no antenatal visits. ${ }^{10}$ This indicates the importance of antenatal care as the single intervention which could influence the occurrence of this serious complication. In unbooked cases the signs and symptoms of preeclampsia remain unrecognized until severe complications such as eclampsia occur.

Antepartum eclampsia $(80.6 \%)$ was more than intrapartum (6.9\%) and postpartum (12.5\%) combined. Similar results were found in a study conducted by Mahram et al in Egypt and in the study conducted by Sibai et al onset of convulsions occurred before delivery in $71 \%$ cases and after delivery $29 \%$. $^{2,11}$

Majority of patients $33(42.8 \%)$ presented at gestational age >37 weeks, $28(36.3 \%)$ patients between 34-37 weeks, and $16(20.77 \%)$ at $<34$ weeks. In study conducted by Sibai et al $>37$ weeks $45.2 \%$ between $27-36$ in $49.2 \%$ and $<27$ in $5.7 \%$. $^{2}$

$68.18 \%$ patients presented with blood pressure $>160 / 110$ mmHg. In a study by Sunita et al, $68 \%$ of eclamptic women had severe hypertension. In the study conducted by Sibai et al $45 \%$ patients had severe hypertension. ${ }^{2,12}$

The number of woman delivered by caesarean section was $48(54.54 \%)$ which is similar to reported by Onuh et al $58.4 \%$ but much lower than reported by Agida et al $(84.8 \%)^{13,14}$

The most common indication of caesarean section in this study was unfavourable cervix in $(62.5 \%)$ patients followed by failed induction in $(16.6 \%)$ patients, fetal distress in $(12.5 \%)$ patients and cephalopelvic disproportion in $(8.33 \%)$ patients, similarly in the study conducted by Efetie et al the most common indication of caesarean section was unfavourable cervix in $78.2 \%$ patients followed by failed induction in $6.5 \%$ patients, fetal distress in $2.2 \%$ patients and cephalopelvic disproportion in $2.2 \%$ patients. $^{8}$
$4.54 \%$ of patients had acute renal failure in this study which is similar to study by Sibai et al who reported acute renal failure in $4.7 \%$, while in the study conducted by Lee et al. ${ }^{2,15}$ Acute renal failure was present in $3 \%$ cases, cerebrovascular accident was $(2.27 \%)$ in our study whereas in study by Onuh et al they reported $5.8 \%$ cases of cerebrovascular accident. ${ }^{13}$ Incidence of HELLP syndrome was $(6.81 \%)$ in our study which is similar to study by Douglas et al who reported $7 \%$ of HELLP syndrome in their study. ${ }^{16} 6.81 \%$ of patients had pulmonary edema in our study.

In study conducted by Chukwuma et al they reported 3\% of pulmonary edema, but Sibai et al reported only $2.9 \%$ of pulmonary edema. ${ }^{2,17} 3.4 \%$ of patients had DIC in our study which is strikingly similar to study by Jido et al showed $3.4 \%$ of DIC in their study. ${ }^{18} 4.54 \%$ of eclamptic patients had abruptio placenta in this study which is similar to study by Raji et al who reported $4.10 \%$ of abruption placentae while Chukwuma et al reported $7 \%$ of abruptio placentae. ${ }^{12,16,19} 4.54 \%$ of patients had postpartum haemorrhage in this study while Bhanu et al reported postpartum haemorrhage in $3.9 \%$ cases. $^{20}$ Cortical blindness was present in $(2.27 \%)$ cases in this study whereas in study by Douglas et al they reported cortical blindness in $<1 \%$ of cases. ${ }^{16}$ Maternal mortality in present study was $(6.81 \%)$, In study conducted by Chukwuma et al maternal mortality was $10 \%$, whereas in study conducted by Sibai et al it was significantly low $0.4 \% .^{2,17}$

Perinatal mortality was $(14.77 \%)$ in current study, which was contributed by $9.09 \%$ of stillbirths and $5.68 \%$ neonatal deaths, In the study by Ndaboine et al perinatal mortality was $20.7 \%$ (stillbirths $12.2 \%$ and neonatal death $8.5 \%$ ), in the study by Mahram et al, it was $38.6 \%$ (stillbirths $2.7 \%$ and neonatal death $9.5 \% \%$ )..$^{11,21}$ There were $(34.09 \%)$ NICU admissions in our study and in the study conducted by Lee et al there were $59 \%$ NICU admissions while in the study conducted by Mahran et al $18.8 \% .{ }^{11,15}$ Prematurity and intrauterine growth restriction were the major cause for neonatal deaths and NICU admissions in this study. As this is an established fact that early deliveries reduce maternal mortality and morbidity however expose the babies to the risks of prematurity.

\section{CONCLUSION}

Eclampsia continue to be significant causes of maternal and fetal morbidity and mortality. Though prevention is not possible, it is important to recognise early warning symptoms and signs so that life threatening complications can be averted. Provision of quality antenatal health care services, increasing patient awareness about warning symptoms, investigations, timely delivery and intensive monitoring in the intrapartum and postpartum period have the potential to improve maternal and perinatal outcome. Education and empowerment of women and accessible health care especially to the socioeconomically deprived and rural population is the need of the hour. 
Funding: No funding sources

Conflict of interest: None declared

Ethical approval: The study was approved by the Institutional Ethics Committee

\section{REFERENCES}

1. Cunningham FG, Leveno KJ, Bloom SL, Hauth JC, Rouse DJ, Catherine YS. Williams Obstetrics. 24th Ed. New York, NY: McGraw Hill Companies; 2014.

2. Sibai BM, Sarinoglu C, Mercer BM. Eclampsia: VII. Pregnancy outcome after eclampsia and long-term prognosis. Am J Obstet Gynecol. 1992;166(6):175763.

3. Health E. Balancing the scales: expanding treatment for pregnant women with life-threatening hypertensive conditions in developing countries. A report on barriers and solutions to treat preeclampsia and eclampsia. Engender Health. 2007.

4. Roberts JM. Endothelial dysfunction in preeclampsia. Semin Reprod Endocrinol. 1998;16:515.

5. Katz VL, Farmer R, Kuller J. Preeclampsia into eclampsia: toward a new paradigm. Am J Obstet Gynaecol. 2000;182:1389-96.

6. Mahalakshmi G, Krishnaveni A, Nimma W, Vinusha $\mathrm{K}$. The study of maternal and perinatal outcome of eclampsia in a tertiary hospital. IOSR J Dental Med Sci. 2016;15(4):123-8.

7. Kannar A, Patel M, Prajapati S, Chavda D. A retrospective study of 100 cases of Eclampsia: perinatal outcomes. Int J Reprod Contracept Obstet Gynecol. 2016;5:3898-901.

8. Efetie ER, Okafor UV. Maternal outcome in eclamptic patients in abuja, nigeria a 5 year review. Nigerian journal of clinical practice. 2007;10(4):30913.

9. Pannu D, Das B, Hazari P, Shilpa. Maternal and perinatal outcome in eclampsia and factors affecting the outcome: a study in North Indian population. Int J Reprod Contracept Obstet Gynecol. 2014;3(2):34751.

10. Nobis PN, Hajong A. Eclampsia in India through the decades. J Obstet Gynecol India. 2016;66(1):172-6.
11. Mahran A, Fares H, Elkhateeb R, Ibrahim M, Bahaa $\mathrm{H}$, Sanad A, et al. Risk factors and outcome of patients with eclampsia at a tertiary hospital in Egypt. BMC Pregnancy Childbirth. 2017;17(1):435.

12. Sunita TH, Desai RM, Hon N, Shinde KJ, Hashmi SI. Eclampsia in a teaching hospital: Incidence, clinical profile and response to magnesium sulfate by Zuspan's regimen. IOSR J Dental Med Sci. 2013;4(2):1-5.

13. Onuh SO, Aisien AO. Maternal and fetal outcome in eclamptic patients in Benin City, Nigeria. J Obstet Gynaecol. 2004;24(7):765-8.

14. Agida TE, Adeka BI, Jibril KA. Pregnancy outcome in eclamptics at the university of Abuja teaching hospital, Gwagwalada, Abuja: a 3 year review. Nigerian J Clin Pract. 2010;13(4):394-8.

15. Lee W, O'Connell CM, Baskett TF. Maternal and perinatal outcomes of eclampsia: Nova Scotia, 19812000. J Obstet Gynaecol Canada. 2004;26(2):119-23.

16. Douglas KA, Redman CW. Eclampsia in the United Kingdom. BMJ. 1994;309(6966):1395-400.

17. Chukwuma B, Ozumbia, Ibe AI. Eclampsia in Enugu, eastern Nigeria. Acta obstetricia et gynecologica Scandinavica. 1993;72(3):189-92.

18. Jido TA. Ecalmpsia: maternal and fetal outcome. Afr Health Sci. 2012;12(2):148-52.

19. Raji C, Poovathi M, Nithya D. Prospective study of fetomaternal outcome in eclampsia in a tertiary care hospital. Int J Reprod Contracept Obstet Gynecol. 2016;5:4329-34.

20. Bhanu BT, Amudha S, Sarojini. Clinical study of maternal complications associated with eclampsia. Int J Reprod Contracept Obstet Gynecol. 2017;6:1905-8.

21. Ndaboine EM, Kuhunrwa A, Rumanyika R, Beatrice $\mathrm{H}$, Massinde AN. Eclamptic and maternal and perinatal outcomes. Afr J Reprod Health. 2012;16:35.

Cite this article as: Agarwal M, Gautam A. Study of fetomaternal outcome in eclampsia. Int J Reprod Contracept Obstet Gynecol 2020;9:4155-9. 